\title{
Photobiomodulation with LEDs And Laboratory Parameters in the Contexts of Oral Mucositis After High-Dose Methotrexate in Children
}

\section{Isabella Melo Brito Ferreira}

CESUPA: Centro Universitario do Estado do Para

Marco Tulio Brazão-silva

Montes Claros State University: Universidade Estadual de Montes Claros

José Miguel Alves Junior

Hospital Oncológico Infantil Octavio Lobo

Kristianne Porta Santos Fernandes

Uninove: Universidade Nove de Julho

Douglas Magno Guimaraes ( $\nabla$ douglas_guima@hotmail.com )

Univesity Center of Para https://orcid.org/0000-0001-7856-1324

\section{Research Article}

Keywords: Methotrexate, Oral mucositis, Photobiomodulation, Febrile neutropenia.

Posted Date: March 30th, 2021

DOl: https://doi.org/10.21203/rs.3.rs-296702/v1

License: (9) This work is licensed under a Creative Commons Attribution 4.0 International License.

Read Full License 


\section{Abstract \\ Purpose}

The present, retrospective cohort study evaluated the efficacy of photobiomodulation (PBM) with LEDs to prevent and treat oral mucositis (OM) in pediatric patients receiving high doses of MTX, and the relationship of the occurrence of $\mathrm{OM}$ with laboratory parameters as possible risk factors for the development of OM.

\section{Methods}

The medical records of children who received high doses of MTX $\left(>2 \mathrm{~g} / \mathrm{m}^{2}\right)$ and photobiomodulation with LEDs were reviewed. Development of OM, hepatic and renal function, hemogram, delayed MTX excretion, febrile neutropenia were analyzed.

\section{Results}

Only 28 cases of OM were observed in the 358 cycles of high-dose MTX analyzed. Oral mucositis was associated with low levels of hemoglobin $(p<0.0001)$, hematocrits $(p<0.0001)$, ALT $(p<0.0001)$, and AST $(p=0.002)$. The risk of developing OM was associated with AST (OR 7.24; $95 \% \mathrm{Cl} 2.56-20.45)$, urea (OR 6.95; 95\% Cl 1.49-32.42), hemoglobin (OR 6.04; 95\% Cl 2.33-15.64), and febrile neutropenia (OR 4.41; $95 \% \mathrm{Cl} 2.89-15.73)$. This risk increases when these parameters are associated.

\section{Conclusion}

The low incidence of mucositis, compared with the literature, indicates that PBM can prevent and reduce the severity of $\mathrm{OM}$, as well as hospitalization time. The risk of $\mathrm{OM}$ development is associated with febrile neutropenia, hematological, and kidney and liver toxicity, with the risk increasing when these factors are associated.

\section{Introduction}

Childhood cancers are a heterogeneous group of disorders that represent approximately $1 \%-2 \%$ of all cancers, with their incidence varying considerably among different regions, being more frequent in countries with a low human development index $[1,2]$. The most common types of cancer affecting these patients are leukemias, lymphomas, osteosarcomas, tumors of the abdomen and central nervous system, and rhabdomyosarcomas [1]. Pediatric tumors are typically treated with high doses of methotrexate (MTX), in particular in the case of leukemia, osteosarcoma, and lymphoma. Methotrexate is a folic acid antagonist that interferes reversibly with the action of several key enzymes, including dihydrofolate- 
reductase, thymidilate synthetase, and amino-imidazolecarboxamide ribosyl-5-phosphate (AICAR) transformylase in the folate pathway [3].

Although MTX is safe and effective for the treatment of pediatric cancers, it may have adverse effects that can lead to the interruption of the treatment, resulting in a poor outcome for the suppression of the cancer [4]. Common adverse effects include acute kidney lesion, myelosuppression, hepatotoxicity, neurotoxicity, and mucositis [4,5]. Oral mucositis (OM) is a debilitating condition that impedes swallowing, eating, drinking, and talking, and requires treatment with opioids, which increases the risk of infection, leading to delays in the chemotherapy, a prolongation of hospital stays, and increased mortality $[6,7]$.

The incidence of OM in children receiving high doses of MTX ranges from $25 \%$ to $75 \%$, with the condition normally initiating 3 to 10 days after the infusion of the chemotherapy, and lasting up to three weeks [7]. A number of studies have investigated potential strategies for the prevention, treatment or alleviation of the symptoms of mucositis [8, 9]. Recently, the Multinational Association of Supportive Care in Cancer and the International Society of Oral Oncology (MASCC/ISOO) published guidelines for the management and prevention of mucositis caused by cancer therapy. These measures include basic oral care, photobiomodulation (PBM), cryotherapy and the application of keratinocyte growth factor to prevent OM in patients undergoing chemotherapy [8]. Although PBM is a recommended protocol to prevent OM in pediatric patients, the procedure needs to be evaluated in greater detail. Photobiomodulation is used to stimulate the biological response of the patient using sources of light, which may include lasers, lightemitting diodes (LEDs), and normal light in the visible and near-infrared spectra at very low, non-thermal doses [10].

Photobiomodulation with LEDs has been proposed as a safe and low-cost alternative tool for the prevention of OM with features similar to those of low-level laser therapy (LLLT) [11, 12](artigo SCC). The present study evaluated the efficacy of LEDs for the prevention and treatment of oral mucositis in pediatric patients receiving high doses of MTX, and identified laboratory parameters that act as risk factors for the development of OM. The study involved a total of 118 patients, all being treated with high doses of MTX. The occurrence of OM, the severity of the inflammation, hospitalization time, MTX secretion, myelossupression, liver and kidney toxicity, and febrile neutropenia were all analyzed.

\section{Patients And Methods}

The present retrospective cohort study was conducted at the "Octavio Lobo" Pediatric Oncology Hospital in Belém, Brazil, following the guidelines of the Strengthening the Reporting of Observational Studies in Epidemiology (STROBE) Statement for cohort studies. The protocols for this study were also approved by the Ethics Committee of the Pará University Center (CESUPA) in Belém, Brazil (82409317.0.0000.5169).

All the patients at this hospital who received high doses of MTX (intravenous infusion of $2 \mathrm{~g} / \mathrm{m} 2$, over 24h) between June 2019 and September 2020 were included in the study. The clinical data on the patients were obtained from the SALUX software (Porto Alegre, RS, Brazil). The inclusion criteria were: 
age of 0-19 years; received the PBM protocol with LED to prevent OM (artigo SCC), and returned for a medical appointment 7-10 days after being discharged from hospital. The exclusion criteria were: patients undergoing radiotherapy of the head and neck; medical records missing the results of the tests conducted after the chemotherapy cycle, and clinical data missing. The variables of interest were: sex; age; MTX excretion (less than $0.2 \mu \mathrm{M}$ in 48 hours); mucositis grade; hemoglobin; hematocrit; platelet, blood cell and neutrophil counts; creatinine; urea; aspartate aminotransferase (AST), alanine aminotransferase (ALT), and febrile neutropenia. The results of these exams were graded according the Common Terminology Criteria for Adverse Events (CTCAE) of National Cancer Institute (NCI), version 5.0.

In a medical appointment, blood samples were collected from each patient, and their oral cavity was examined by a qualified dentist to identify the potential oral complications of chemotherapy. The World Health Organization (WHO) scale was used to grade the patients: grade $0=$ no mucositis; grade $1=$ erythema with no lesions; grade 2 = presence of ulcers, but patient able to eat; grade 3 = painful ulcers, but patient able to consume liquid food with analgesia; grade $4=$ requires parenteral or enteral support and continuous analgesia. Patients diagnosed with OM were evaluated and received PBM with LEDs on a daily basis. The PBM was applied using a cluster of 6 red $(660 \pm 20 \mathrm{~nm})$ LEDs (Cosmedical, SP, Brazil). The LEDs were applied using the following dosimetric parameters: power output $5 \mathrm{~mW}$, exposure time of 120 seconds, radiant exposure of $2 \mathrm{~J} / \mathrm{cm} 2$, and $0.6 \mathrm{~J}$ per point. The CT cycles were divided into two groups, those with OM and those with no OM.

\section{Statistical analysis}

The data are presented as the frequency, mean, standard deviation (SD), median, and percentiles, depending on the parameter analyzed. The data were first analyzed using descriptive and inferential statistics, followed by logistic regression run in Graphpad Prism 5 (GraphPad Software, La Jolla, California, USA) and BioEstat 5.0 (Instituto Mamiraua, Tefé, Amazonas, Brazil). The categorical values were dichotomized $(0 / 1)$ based on the CTCAE/ $\mathrm{NCl}$ guidelines, and are summarized in Table 1 . The chemotherapy cycles with missing laboratory data or no follow-up information were excluded from the analyses. 
Table 1

The dichotomization of the variables for the logistic regression analyses run in the present study.

\begin{tabular}{|c|c|c|}
\hline \multirow[t]{2}{*}{ Variable } & \multicolumn{2}{|c|}{ Dichotomized category } \\
\hline & 0 & 1 \\
\hline Sex & Female & Male \\
\hline Age & $\leq 6$ years old & $>$ 6years old \\
\hline Hemoglobin & $\geq 8 \mathrm{~g} / \mathrm{dL}$ & $<8 \mathrm{~g} / \mathrm{dL}$ \\
\hline Hematocrit & $\geq 30 \%$ & $<30 \%$ \\
\hline White blood cells & $\geq 2 \times 10^{3}$ cells $/ \mathrm{mm}^{3}$ & $<2 \times 10^{3}$ cells $/ \mathrm{mm}^{3}$ \\
\hline Neutrophil & $\geq 10^{3} / \mathrm{mm}^{3}$ & $<10^{3} / \mathrm{mm}^{3}$ \\
\hline Platelet & $\geq 50 \times 10^{3} / \mathrm{mm}^{3}$ & $<50 \times 10^{3} / \mathrm{mm}^{3}$ \\
\hline Urea & $\leq 48 \mathrm{mg} / \mathrm{dL}$ & $>48 \mathrm{mg} / \mathrm{dL}$ \\
\hline Creatinine & $\leq 0.7$ & $>0.7$ \\
\hline Aspartate aminotransferase (AST) & $\leq 120 \mathrm{U} / \mathrm{L}$ & $>120 \mathrm{U} / \mathrm{L}$ \\
\hline Alanine aminotransferase (ALT) & $\leq 123 \mathrm{U} / \mathrm{L}$ & $>123 \mathrm{U} / \mathrm{L}$ \\
\hline Febril neutopenile (FN) & Absent & Present \\
\hline Delayed MTX excretion & Absent & Present \\
\hline
\end{tabular}


Table 2

Characteristics and clinical parameters of the 118 participants in the present study, including their gender, age, diseases, CT protocol and oral complications following CT.

\begin{tabular}{|c|c|c|}
\hline Characteristic & $\mathrm{n}$ & $\%$ \\
\hline \multicolumn{3}{|l|}{ Gender } \\
\hline Male & 68 & $57 \%$ \\
\hline Female & 50 & $43 \%$ \\
\hline \multicolumn{3}{|l|}{ Age } \\
\hline $0-6$ years & 51 & $43 \%$ \\
\hline $7-12$ years & 34 & $29 \%$ \\
\hline$>13$ years & 33 & $28 \%$ \\
\hline \multicolumn{3}{|l|}{ Diseases } \\
\hline ALL & 79 & $67 \%$ \\
\hline Osteosarcoma & 16 & $14 \%$ \\
\hline AML & 6 & $5 \%$ \\
\hline Lymphoma & 10 & $8 \%$ \\
\hline Others sarcomas & 7 & $6 \%$ \\
\hline \multicolumn{3}{|l|}{ CT protocol } \\
\hline BFM 2009 & 62 & $52 \%$ \\
\hline GLATO & 13 & $11 \%$ \\
\hline RE-LLA & 9 & $8 \%$ \\
\hline BFM 95 & 8 & $7 \%$ \\
\hline BFM 2002 & 6 & $5 \%$ \\
\hline COG & 4 & $3 \%$ \\
\hline AML 2002 & 4 & $3 \%$ \\
\hline Brasileiro & 2 & $2 \%$ \\
\hline Interfant & 2 & $2 \%$ \\
\hline RXVII & 2 & $2 \%$ \\
\hline
\end{tabular}

ALL: Acute Lymphoblastic Leukemia; AML: Acute Myeloblastic Leukemia; CT: chemotherapy; GLATO: Latin American Group of Osteosarcoma Treatment; COG: Children's Oncology Group; ANUG: Acute Necrotizing Ulcerative Gingivitis 


\begin{tabular}{|lll|}
\hline Characteristic & $\mathbf{n}$ & $\%$ \\
\hline Other & 6 & $5 \%$ \\
\hline Oral complications & 28 & $58 \%$ \\
\hline Mucositis & 11 & $22 \%$ \\
\hline Candidiasis & 3 & $6 \%$ \\
\hline Petechiae & 2 & $4 \%$ \\
\hline Herpes & 2 & $4 \%$ \\
\hline Pericoronaritis & 2 & $4 \%$ \\
\hline ANUG & 1 & $2 \%$ \\
\hline Abscess & $2 \%$. & \\
\hline $\begin{array}{l}\text { ALL: Acute Lymphoblastic Leukemia; AML: Acute Myeloblastic Leukemia; CT: chemotherapy; GLATO: } \\
\text { Latin American Group of Osteosarcoma Treatment; COG: Children's Oncology Group; ANUG: Acute }\end{array}$ & \\
\hline Necrotizing Ulcerative Gingivitis & & \\
\hline
\end{tabular}

The initial analyses were based on $t$ tests of the unadjusted means between patients with $\mathrm{OM}$ and those with no OM. The dichotomized data were then evaluated using a bivariate analysis, with the adjusted odds ratio being obtained using a multiple regression. The multiple regression model included the four variables with the lowest $p$ values obtained in the bivariate model.

\section{Results}

A total of 123 patients were treated using high doses of MTX during the study period, although five were excluded from the present study due to the lack of data on the chemotherapy protocol or syndrome association, which left 118 patients that were included in the analyses (Fig. 1). A total of 364 chemotherapy cycles were analyzed, although six cycles were excluded due to the lack of laboratory data, resulting in a final total of 358 cycles (Fig. 1). The most common diagnoses were Acute Lymphoblastic Leukemia, ALL (72 patients, $61 \%$ of the total), osteosarcoma (16 patients, $14 \%$ ), and Acute Myeloid Leukemia, AML (6 patients, 5\%). All patients received at least $2 \mathrm{~g} / \mathrm{m} 2$ of MTX. The principal CT protocols were BFM2009 (52\% of the patients), GLATO (11\%), RE-LLA (8\%), BFM 2002 (5\%) and COG (3\%), with the GLATO and COG protocols being applied to solid tumors and the others to leukemia and lymphomas. The principal oral complaints following the CT cycle were OM (58\% of the complaints), candidiasis (22\%), petechiae (6\%), and herpes labialis (4\%).

Oral mucositis (OM) was diagnosed in 28 of the $358 \mathrm{MTX}$ cycles, of which 10 (35.7\%) cases were classified as grade 1, $12(42.9 \%)$ as grade 2 , and six (21.4\%) were classified as grade 3 on the WHO scale. Overall, $67.9 \%$ (19) of these cases were recorded in patients with leukemia, $17.9 \%$ (5) in patients with osteosarcoma, and $14.2 \%$ (4) of the cases were recorded in patients with lymphomas. Hospitalization time was up to 8.1 days for the treatment of the patients with grade $1 \mathrm{OM}$, up to 14.5 days for patients 
with grade 2 OM, and up to 15.8 days for those with grade 3 OM. Valer et al. 2020 [6] analyzed 255 cycles of high-dose MTX in pediatric cancer without any prophylactic procedures for the prevention OM, and recorded a prevalence of OM of $74.9 \%$ (191 cycles). Comparing these findings with those of the present study using Fisher's exact test, the patients treated with LEDs had a $90 \%$ better chance $(\mathrm{RR}=0.1 ; 95 \% \mathrm{Cl}=$ $0.07265-0.1501$ ) of not developing OM in comparison with the patients that who have not received preventive PBM treatment.

In the comparison of the laboratory parameters, the t-test revealed no association of $\mathrm{OM}$ with the platelet, blood cell or neutrophil counts, creatinine or urea (Table 3), although a significant difference was found in hemoglobin, hematocrits, aspartate aminotransferase (AST), and alanine aminotransferase (ALT). However, when the values were dichotomized for a simple logistic regression (Table 4), OM was associated hemoglobin, white blood cell count, urea, ALT, AST, and febrile neutropenia.

Table 3

The results of the $t$ tests comparing the mean clinical parameters between the groups of patients with oral mucositis or no OM.

\begin{tabular}{|c|c|c|c|c|c|}
\hline \multirow[t]{2}{*}{ Parameter } & \multicolumn{2}{|l|}{ No OM } & \multicolumn{2}{|c|}{ Presence of $\mathrm{OM}$} & \multirow[t]{2}{*}{$p$} \\
\hline & Median & SD & Median & SD & \\
\hline Hemoglobin (g/dL) & 11.24 & 0.10 & 9.474 & 0.3502 & $<0.0001$ \\
\hline Hematocrit (\%) & 33.77 & 0.29 & 29.15 & 0.9281 & $<0.0001$ \\
\hline Leukocyte count (cells/mm³) & 4788 & 308 & 5549 & 2532 & 0.05483 \\
\hline Neutrophil count (cells/mm³) & 2198 & 116.4 & 3363 & 1669 & 0.076 \\
\hline Platelet Count $\left(/ \mathrm{mm}^{3}\right)$ & 203929 & 6792 & 198571 & 32095 & 0.87 \\
\hline Urea (mg/dL) & 22.03 & 0.57 & 22.71 & 1.99 & 0.72 \\
\hline Creatinine & 0.38 & 0.001 & 0.35 & 0.017 & 0.23 \\
\hline $\operatorname{ALT}(\mathrm{U} / \mathrm{L})$ & 64.69 & 4.8 & 153.4 & 50.60 & $<0.0001$ \\
\hline AST (U/L) & 45.6 & 4.41 & 77.6 & 19.07 & 0.002 \\
\hline
\end{tabular}


Table 4

The simple logistic regression of the clinical and laboratory parameters on the risk of oral mucositis in the present study.

\begin{tabular}{|llll|}
\hline Parameter & \multicolumn{3}{l}{ Oral Mucositis } \\
\cline { 2 - 4 } & Odds Ratio & $\boldsymbol{p}$ & $\mathbf{9 5 \%} \mathrm{Cl}$ \\
\hline Gender & 0.8 & 0.53 & $0.40-1.6$ \\
\hline Age $>$ 6 years & 0.72 & 0.35 & $0.36-1.44$ \\
\hline Hemoglobin & $\mathbf{6 . 0 4 8}$ & $\mathbf{0 . 0 0 0 2}$ & $2.33-15.64$ \\
\hline Hematocrits & 1.122 & 0.45 & $0.89-1.60$ \\
\hline Leukocyte count & $\mathbf{3 . 3 8 9 6}$ & $\mathbf{0 . 0 0 1 2}$ & $1.62-7.08$ \\
\hline Neutrophil count & 1.8867 & 0.0809 & $0.93-3.76$ \\
\hline Platelet count & 1.5222 & 0.3824 & $0.59-3.91$ \\
\hline Urea & $\mathbf{6 . 9 5 4 5}$ & $\mathbf{0 . 0 1 3 5}$ & $1.49-32.42$ \\
\hline Creatinine & 0.0001 & 0.8140 & \\
\hline ALT & $\mathbf{2 . 7 5 3 0}$ & $\mathbf{0 . 0 1 3 6}$ & $1.23-6.15$ \\
\hline AST & $\mathbf{7 . 2 4}$ & $\mathbf{0 . 0 0 2}$ & $2.56-20.45$ \\
\hline Febrile neutropenia & $\mathbf{4 . 4 1}$ & $<\mathbf{0 . 0 0 0 1}$ & $2.89-15.73$ \\
\hline Delayed MTX excretion & 1.623 & 0.34 & $0.89-2.12$ \\
\hline
\end{tabular}

The variables with the highest odds ratios (ORs) were AST (OR $=7.24 ; 95 \% \mathrm{Cl}=2.56-20.45)$, urea (OR = $6.95 ; 95 \% \mathrm{Cl}=1.49-32.42)$, hemoglobin $(\mathrm{OR}=6.04 ; 95 \% \mathrm{Cl}=2.33-15.64)$, and febrile neutropenia $(\mathrm{OR}=$ $4.41 ; 95 \% \mathrm{Cl}=2.89-15.73)$. These four variables were paired for multiple logistic regression to determine their potential interaction (Table 5). In this case, the OR of the interaction between hemoglobin and AST was $8.27(95 \% \mathrm{Cl}=2.83-24.17)$, while that recorded between hemoglobin and febrile neutropenia was $7.59(95 \% \mathrm{Cl}=3.14-18.38), 6.96$ between urea and febrile neutropenia $(95 \% \mathrm{Cl}=2.95-16.42), 6.66$ between hemoglobin and urea $(95 \% \mathrm{Cl}=1.34-33.26), 6.30$ between urea and AST was $6.30(95 \% \mathrm{Cl}=$ 2.16-18.39), and 5.63 between AST and febrile neutropenia $(95 \% \mathrm{Cl}=2.32-13.67)$. 
Table 5

The multiple logistic regression of the combination of different laboratory parameters on the risk of oral mucositis in the patients analyzed in the present study.

\begin{tabular}{|llll|}
\hline Combination of parameters & Odds Ratio & $\boldsymbol{P}$ & 95\% Confidence Interval \\
\hline $\mathrm{Hb}+$ Urea & 6.669 & 0.02 & $1.34-33.26$ \\
\hline $\mathrm{Hb}+\mathrm{AST}$ & 8.275 & 0.0001 & $2.83-24.17$ \\
\hline $\mathrm{Hb}+\mathrm{NF}$ & 7.594 & $<0.0001$ & $3.14-18.38$ \\
\hline Urea + AST & 6.302 & 0.0008 & $2.16-18.39$ \\
\hline Urea + NF & 6.960 & $<0.0001$ & $2.95-16.42$ \\
\hline AST + NF & 5.636 & 0.0001 & $2.32-13.67$ \\
\hline Hb: hemoglobin; NF: febrile neutropenia; AST: Aspartate aminotransferase
\end{tabular}

\section{Discussion}

High-dose MTX is important in consolidation chemotherapy when treating pediatric patients with leukemia, lymphomas, osteosarcoma, and other childhood malignancies. The side effects of high-dose MTX vary considerably among individuals, and may require adjustments to the treatment, with survival being impaired in the most serious cases. Oral mucositis (OM) is the most frequent toxic outcome [4]. Our previous study suggested that PBM with LEDs has similar effects to low-level laser therapy (LLLT). Given this, LEDs were adopted for the prevention and treatment of OM related to high-dose MTX, and the results of the present study indicate that the prevalence of OM associated with CT cycles may be reduced by more than $90 \%$, although correlations were found with clinical parameters, such as hemoglobin, urea, and AST.

A number of techniques, including PBM, have been suggested for the prevention of $\mathrm{OM}$. The MASCC/ISOO recommended the PBM with LLLT to prevent OM with a high level of support from the empirical evidence [8]. However, a review of the evidence found that it was not possible to define universal guidelines for the use of intra-oral PBM in the prevention of OM in cancer patients treated with CT due to the considerable variability in the PBM protocols. The protocol used in the present study consisted of the daily application of red light at $660 \mathrm{~nm}$, with a power output of $5 \mathrm{~mW}$, a total of six points per area, and exposure time of 120 seconds, leading to a radiant exposure of $2 \mathrm{~J} / \mathrm{cm}^{2}$, or $0.6 \mathrm{~J}$ per point. These parameters are similar to those adopted in other studies [13-16] which suggested $2 \mathrm{~J} / \mathrm{cm} 2$ an optimal radiation dose to prevent and reduce the incidence of severe OM induced by chemotherapy.

Severe OM affects the patients' health and quality of life, and increases hospital costs though the need for enteral or parenteral nutrition, systemic analgesics, prolonged hospital stays, and increased mortality [10]. Elting and Chang reported an incremental cost of OM is around $\$ 3700$ per cycle among patients receiving $\mathrm{CT}$ [17]. We did not estimate the reduction in hospital costs associated with the application of 
PBM with LEDs, although the incidence of OM was reduced to approximately $7 \%$, there were no cases of grade $4 \mathrm{OM}$ and only six cases of grade $3 \mathrm{OM}$, and mean hospitalization time was reduced considerably in comparison with the normal treatment of OM [7].

The most commonly-described side effects of MTX therapy are myelosuppression, acute liver toxicity, nephrotoxicity, mucositis, and neurotoxicity [18], in addition to the risk of development of OM. Low hemoglobin levels have been shown to be risk factor for the development of OM. Neutropenia and lymphopenia are common in patients with hematologic malignancies, and may also arise as an adverse effect of the treatment of these disorders, and these conditions appear to be associated with a higher risk of the bacterial colonization of the damaged epithelium, leading to the aggravation of OM $[9,19]$. The present study did not reveal any association between OM and low counts of lymphocyte, platelets or neutrophils, although there was an association with febrile neutropenia, which indicates that this infection and the associated inflammatory response may play an important role in the development of $\mathrm{OM}$. The data collected in the present study do not allow the interpretation of any temporal relationship, however, that is, whether febrile neutropenia is a precursor of $\mathrm{OM}$, or vice-versa.

A number of risk factors have been related to the development of OM, such as delayed MTX excretion [20-23], although not all the studies have found a correlation between mucositis (oral or gastrointestinal) and high plasma concentrations of MTX $[6,24,25]$. The present study found no significant correlation between the development of OM and the MTX excreted $72 \mathrm{~h}$ after the infusion. This indicates that the plasma levels after $72 \mathrm{~h}$ may not be a good indicator of toxicity, and that the evaluation of the liver and kidney from peripheral blood would likely be more valuable. It is important to note, however, that the use of LED in the present study may have masked the potential for predicting these markers, due to the increased resistance of the oral mucosa

Methotrexate (MTX) is a dihydrofolate reductase inhibitor that can reduce hepatic folate stocks and toxicity due to local folate deficiency, increasing the levels of transaminase [26]. During high-dose intravenous MTX, serum transaminase levels may rise to 10-20 times the normal upper limit within 1248 hours, although they may then fall rapidly back to normal with only rare cases of jaundice or symptoms of liver injury [27]. Liver enzymes are elevated in children treated with prolonged high doses of MTX, although no correlation has been found between liver toxicity and OM in individuals protected with LED applications to the oral mucosa $[6,22,28]$. The results of the present study indicated that high levels of AST after at least 7 days may predict hepatic injury and OM in patients submitted to PBM with LEDs. It would thus appear to be reasonable to assume that PBM with LED improves the resistance of the oral mucosa to MTX toxicity, and that the progression to OM will occur only toxicity is high enough to cause damage to other organs.

Renal toxicity is a major concern in patients receiving high doses of MTX, occurring in 2-12\% of patients [4]. This nephrotoxicity can be reduced by prior hyperhydration and urine alkalization, given that a neutral $\mathrm{pH}$ increases the solubility and excretion of MTX, which reduces the formation of crystals in the renal tubules [4]. In the present study, all 358 high doses MTX cycles were preceded by hyperhydration and 
urine alkalization, which evolved to high levels of creatinine in 18 cases (none of which developed OM) and high urea in seven cases (of which, five had OM). High levels of urea have been associated with a type of oral ulceration known as uratemic stomatitis, due to the reaction of tissue to toxins or uratemic catabolites, or the hydrolyzing action of the oral bacterial flora on the urea, which results in the formation of irritant ammonium compounds [29]. This suggests that high levels of urea can be used as an indicator of MTX toxicity, and increasing OM. These findings reinforce the need for the investigation of more effective preventive measures in this group of patients.

Overall, then, oral mucositis is one of the most problematic complication in children being treated with high doses of MTX. However, the present study showed that photobiomodulation with LEDs may both prevent $\mathrm{OM}$ and reduce the severity of this disorder, as well as decreasing hospitalization time. The risk of developing OM was associated with febrile neutropenia, hematological, kidney, and liver toxicity, and this risk is exacerbated when these factors are associated with one another.

\section{Declarations}

Funding: Not applicable

Conflicts of interest/Competing interests: The authors declare that they have no conflict of interest.

Ethics approval: All procedures performed in studies involving human participants were in accordance with the ethical standards of the institutional and/or national research committee and with the 1964 Helsinki Declaration and its later amendments or comparable ethical standards. The study was approved by the Bioethics Committee of the University Center of Pará (\#82409317.0.0000.5169)

Consent to participate: Informed consent was obtained from legal guardians and individual participants included in the study.

Consent for publication Patients signed informed consent regarding publishing their data and photographs.

Availability of data and material: Not applicable

Code availability: Not applicable

Authors' contributions: DOUGLAS MAGNO GUIMARAES- Conceptualization, formal analysis, Writing original draft

ISABELLA MELO BRITO FERREIRA- Data acuration, investigation, methodology

MARCO TULLIO BRAZAO-SILVA- Investigation, methodology

FABIO DE LUCAS DA SILVA ALMEIDA- Investigation, methodology 
JOSE MIGUEL ALVES JUNIOR- Investigation

KRISTIANNE PORTA SANTOS FERNANDES- Conceptualization, Methodology, Writing - review \& editing

\section{References}

1. Piñeros M, Mery L, Soerjomataram I, et al (2020) Scaling Up the Surveillance of Childhood Cancer: A Global Roadmap. JNCl: Journal of the National Cancer Institute djaa069. https://doi.org/10.1093/jnci/djaa069

2. Steliarova-Foucher E, Colombet M, Ries LAG, et al (2017) International incidence of childhood cancer, 2001-10: a population-based registry study. The Lancet Oncology 18:719-731. https://doi.org/10.1016/S1470-2045(17)30186-9

3. Panja S, Khatua DK, Halder M (2018) Simultaneous Binding of Folic Acid and Methotrexate to Human Serum Albumin: Insights into the Structural Changes of Protein and the Location and Competitive Displacement of Drugs. ACS Omega 3:246-253. https://doi.org/10.1021/acsomega.7b01437

4. Howard SC, McCormick J, Pui C, et al (2016) Preventing and Managing Toxicities of High-Dose Methotrexate. The Oncologist 21:1471-1482. https://doi.org/10.1634/theoncologist.2015-0164

5. Liu S-G, Gao C, Zhang R-D, et al (2017) Polymorphisms in methotrexate transporters and their relationship to plasma methotrexate levels, toxicity of high-dose methotrexate, and outcome of pediatric acute lymphoblastic leukemia. Oncotarget 8:37761-37772. https://doi.org/10.18632/oncotarget.17781

6. Valer JB, Curra M, Gabriel A de F, et al (2020) Oral mucositis in childhood cancer patients receiving high-dose methotrexate: Prevalence, relationship with other toxicities and methotrexate elimination. Int J Paediatr Dent ipd.12718. https://doi.org/10.1111/ipd.12718

7. Mazhari F, Shirazi AS, Shabzendehdar M (2019) Management of oral mucositis in pediatric patients receiving cancer therapy: A systematic review and meta-analysis. Pediatr Blood Cancer 66:e27403. https://doi.org/10.1002/pbc.27403

8. Elad S, Cheng KKF, Lalla RV, et al (2020) MASCC/ISOO clinical practice guidelines for the management of mucositis secondary to cancer therapy. Cancer 126:4423-4431. https://doi.org/10.1002/cncr.33100

9. On behalf of The Mucositis Study Group of the Multinational Association of Supportive Care in Cancer/International Society of Oral Oncology (MASCC/ISOO), Zadik Y, Arany PR, et al (2019) Systematic review of photobiomodulation for the management of oral mucositis in cancer patients and clinical practice guidelines. Support Care Cancer 27:3969-3983. https://doi.org/10.1007/s00520-019-04890-2

10. Schubert MM, Eduardo FP, Guthrie KA, et al (2007) A phase III randomized double-blind placebocontrolled clinical trial to determine the efficacy of low level laser therapy for the prevention of oral 
mucositis in patients undergoing hematopoietic cell transplantation. Support Care Cancer 15:11451154. https://doi.org/10.1007/s00520-007-0238-7

11. Genot-Klastersky MT, Klastersky J, Awada F, et al (2008) The use of low-energy laser (LEL) for the prevention of chemotherapy-and/or radiotherapy-induced oral mucositis in cancer patients: results from two prospective studies. Support Care Cancer 16:1381-1387. https://doi.org/10.1007/s00520008-0439-8

12. Zanin T, Zanin F, Carvalhosa AA, et al (2010) Use of 660-nm Diode Laser in the Prevention and Treatment of Human Oral Mucositis Induced by Radiotherapy and Chemotherapy. Photomedicine and Laser Surgery 28:233-237. https://doi.org/10.1089/pho.2008.2242

13. Moraes JJC, Queiroga AS, Biase RCCG, et al (2009) The effect of low level laser therapy in different wavelengths in the treatment of oral mucositis-proposal for extra-oral implementation. Laser Phys 19:1912-1919. https://doi.org/10.1134/S1054660X09170150

14. Elting LS, Chang Y-C (2019) Costs of Oral Complications of Cancer Therapies: Estimates and a Blueprint for Future Study. JNCI Monographs 2019:Igz010.

https://doi.org/10.1093/jncimonographs/lgz010

15. Özdemir ZC, Bozkurt Turhan A, Düzenli Kar Y, Bör Ö (2016) The frequency of hepatotoxicity and myelotoxicity in leukemic children with different high doses of methotrexate. International Journal of Pediatrics and Adolescent Medicine 3:162-168. https://doi.org/10.1016/j.ijpam.2016.08.008

16. Cinausero M, Aprile G, Ermacora P, et al (2017) New Frontiers in the Pathobiology and Treatment of Cancer Regimen-Related Mucosal Injury. Front Pharmacol 8:354. https://doi.org/10.3389/fphar.2017.00354

17. Damascena LCL, de Lucena NNN, Ribeiro ILA, et al (2020) Severe Oral Mucositis in Pediatric Cancer Patients: Survival Analysis and Predictive Factors. IJERPH 17:1235. https://doi.org/10.3390/ijerph17041235

18. Park JA, Shin HY (2016) Influence of genetic polymorphisms in the folate pathway on toxicity after high-dose methotrexate treatment in pediatric osteosarcoma. Blood Res 51:50. https://doi.org/10.5045/br.2016.51.1.50

19. He M, Zhang B, Shen N, et al (2018) A systematic review and meta-analysis of the effect of low-level laser therapy (LLLT) on chemotherapy-induced oral mucositis in pediatric and young patients. European Journal of Pediatrics 177:7-17. https://doi.org/10.1007/s00431-017-3043-4

20. Cheng KK-F (2008) Association of plasma methotrexate, neutropenia, hepatic dysfunction, nausea/vomiting and oral mucositis in children with cancer. Eur J Cancer Care 17:306-311. https://doi.org/10.1111/j.1365-2354.2007.00843.x

21. Rask C, Albertioni F, Bentzen SM, et al (1998) Clinical and Pharmacokinetic Risk Factors for Highdose Methotrexate-induced Toxicity in Children with Acute Lymphoblastic Leukemia: A Logistic Regression Analysis. Acta Oncologica 37:277-284. https://doi.org/10.1080/028418698429586

22. den Hoed MAH, Lopez-Lopez E, te Winkel ML, et al (2015) Genetic and metabolic determinants of methotrexate-induced mucositis in pediatric acute lymphoblastic leukemia. The Pharmacogenomics 
Journal 15:248-254. https://doi.org/10.1038/tpj.2014.63

23. Oliff A, Bleyer WA, Poplack DG (1979) Methotrexate-induced oral mucositis and salivary methotrexate concentrations. Cancer Chemother Pharmacol 2:. https://doi.org/10.1007/BF00258300

24. Conway R, Carey JJ (2017) Risk of liver disease in methotrexate treated patients. WJH 9:1092. https://doi.org/10.4254/wjh.v9.i26.1092

25. (2012) Methotrexate. In: LiverTox: Clinical and Research Information on Drug-Induced Liver Injury. National Institute of Diabetes and Digestive and Kidney Diseases, Bethesda (MD)

26. Weinblatt ME, Dixon JA, Falchuk KR (2000) Serious liver disease in a patient receiving methotrexate and leflunomide. Arthritis Rheum 43:2609-2611. https://doi.org/10.1002/15290131(200011)43:11<2609::AID-ANR32>3.0.CO;2-R

27. Ruospo M, Palmer SC, Craig JC, et al (2014) Prevalence and severity of oral disease in adults with chronic kidney disease: a systematic review of observational studies. Nephrology Dialysis Transplantation 29:364-375. https://doi.org/10.1093/ndt/gft401

\section{Figures}


Assessed for eligibility $(n=123)$

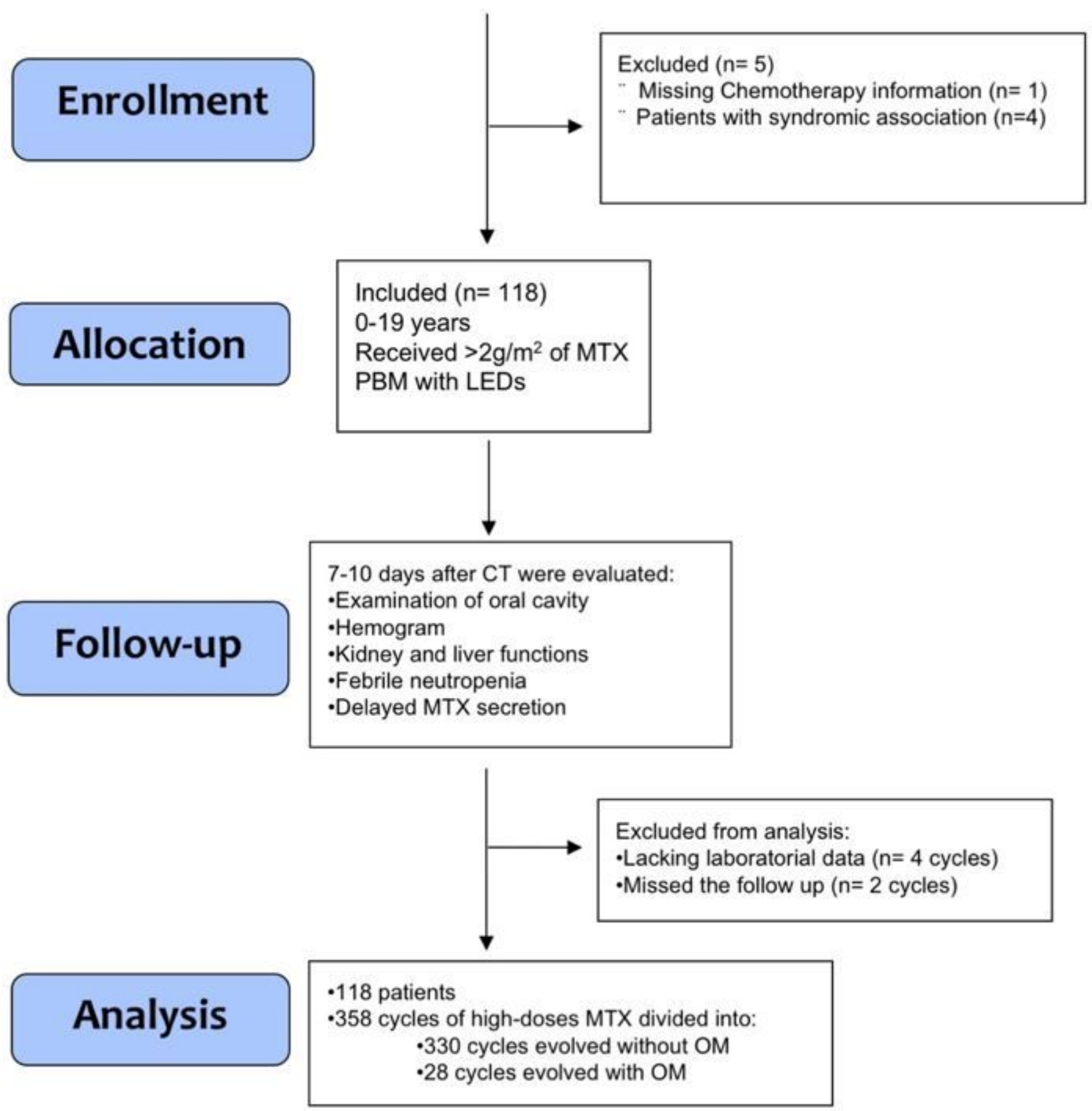

\section{Figure 1}

Flowchart of the selection of the patients for the present study 